\title{
Cardiac Electrophysiologic Interactions of Bepridil, a New Calcium Antagonist, With Enflurane, Halothane, and Isoflurane
}

Lawrence O. Larson, MD, Charles B. Hantler, MD, Joseph J. Lynch, PhD, Steven N. Landau, MD, John A. Buben, PhD, B.R. Lucchesi, MD, PhD, and Paul R. Knight, MD, PhD

\begin{abstract}
Bepridil is an investigational calcium antagonist that also has fast sodium channel blocking and antidysrhythmic properties. In the present study, the potential interactions of bepridil with volatile anesthetics on cardiac electrophysiologic parameters were evaluated in open-chest dogs. Twenty-four dogs anesthetized with enflurane $(n=6)$, halothane $(n=6)$, isoflurane $(n=6)$, or chloralose $(n=6)$ received 2.5 $\mathrm{mg} / \mathrm{kg}$ of bepridil intravenously (IV). Twenty-five additional dogs anesthetized with enflurane $(n=7)$. halothane $(n=6)$, isoflurane $(n=6)$, or chloralose $(\mathrm{n}=6)$, received bepridil, $5.0 \mathrm{mg} / \mathrm{kg}$, IV. Dogs anesthetized with cloralose served as controls. Cardiac electrophysiologic parameters were measured after the dogs were anesthetized and were repeated 5. $15,30,45$, and 60 minutes after bepridil infusion. Plasma bepridil concentrations were also determined at the above time points. Synergy between
\end{abstract}

$\mathbf{B}^{\mathrm{E}}$ EPRIDIL, a calcium antagonist, has been used extensively in Europe as an antianginal agent. ${ }^{1-3}$ It differs from the calcium antagonists currently available in the United States (diltiazem, verapamil, and nifedipine) in several ways. ${ }^{4}$ The half-life of orally administered bepridil is $33+15$ hours, which is considerably longer than the half-lives of currently available calcium antagonists. ${ }^{5,6}$ Bepridil is also known to act at the sodium channel, and possibly the potassium channel, producing quinidine-like effects on the cardiac action potential. ${ }^{7}$ In electrophysiologic experiments, bepridil possesses both slow calcium and fast sodium channel inhibitory activities, while other electrophysiologic studies suggest that it may possess class III antidysrhythmic properties. $^{8}$ Bepridil is also reported to prevent reperfusion-induced tachyarrhythmias and ventricular fibrillation in the unanesthetized $\operatorname{dog}$.

From the Department of Anesthesiology, University of Michigan Medical Center, Ann Arbor.

Address reprint requests to Lawrence O. Larson, $M D$, Instructor in Anesthesiology, University of Michigan Medical Center, 1500 E Medical Center Dr, Ann Arbor, MI 48109.

(c) 1988 by Grune \& Stratton, Inc.

0888-6296/88/0203-0012803.00/0 bepridil and enflurane was demonstrated in the following cardiac electrophysiologic parameters: depression of sinus node function as evidenced by severe depression of sinus node automaticity and conduction; depression of atrioventricular function as evidenced by prolongation of the atrial-His bundle interval and the Wenckebach R-R interval; and, prolongation of the atrial effective refractory period. No synergy was demonstrated between bepridil and halothane or isoflurane when compared to bepridil's effects during chloralose anesthesia. It is concluded that significant synergistic cardiac electrophysiologic effects exist between bepridil and enflurane in dogs. It is recommended that caution be used when anesthetizing patients receiving bepridil with enflurane until human data on the use of this combination of pharmacologic agents is available.

(c) 1988 by Grune \& Stratton, Inc.

It has been suggested that the volatile anesthetics, because of their intrinsic calcium channel-blocking effects, could interact with bepridil resulting in significant cardiovascular side-effects. ${ }^{10-12}$ Verapamil and diltiazem have potent interactions with enflurane that have not been demonstrated with halothane or isoflurane. ${ }^{13.14}$ Severe sinus node depression and advanced $A V$ nodal block occur when verapamil is administered to animals anesthetized with enflurane, but not in animals anesthetized with halothane or isoflurane. ${ }^{14}$

The cardiac electrophysiologic interactions between the volatile anesthetics and two intravenously (IV) administered doses of bepridil were examined in this experiment. Dogs anesthetized with chloralose and given the same doses of bepridil served as controls for this experiment. Because bepridil also possesses class I antidysrhythmic properties, the effects of these interactions on atrial and ventricular refractory periods were examined, as well as their effects on sinus and atrioventricular node function.

\section{MATERIALS AND METHODS}

Forty-nine mongrel dogs weighing 8 to $15 \mathrm{~kg}$ were divided into eight groups. Animals in groups $1(\mathrm{n}=6)$ and 2 $(n=6)$ were given $10 \mathrm{mg}$ of diazepam to prevent seizures, induced with $120 \mathrm{mg} / \mathrm{kg}$ of IV chloralose, and maintained 
with $50 \mathrm{mg} / \mathrm{kg} / \mathrm{h}$ of IV chloralose for the entire experiment. Although lower doses of chloralose have been used in the past, it was found that the dose used was necessary to ensure hemodynamic stability of the model (ie, stable pulse rate and blogd pressure). Since chloralose has been shown to be an anesthetic with minimal effects on cardiac electrophysiologic parameters, these animals served as control groups for the experiment. ${ }^{15}$ Animals in groups $3(n=6)$ and $4(n=6)$ underwent inhalation induction with halothane and were maintained at $1.3 \%$ halothane end-tidal concentration $(\mathrm{MAC}=0.87 \%)$ throughout the experiment. Animals in groups $5(\mathrm{n}=6)$ and $6(\mathrm{n}=7)$ underwent inhalation induction with enflurane and were maintained at $3.3 \%$ enflurane $(\mathrm{MAC}=2.2 \%)$ end-tidal concentration throughout the experiment. Animals in groups $7(n=6)$ and $8(n=6)$ underwent inhalation induction with isoflurane and were mantained at $2.2 \%$ isoflurane $(\mathrm{MAC}=1.48 \%$ ) end-tidal concentration throughout the experiment. End-tidal anesthetic concentrations were monitored using a Perkin-Elmer Model 1100 medical gas analyzer.

After induction, femoral arterial and venous catheters were inserted. Hydration was maintained during the experiment by infusion of 1,500 to $2,500 \mathrm{~mL}$ of lactated Ringer's solution. The rate of infusion was adjusted to maintain a constant blood pressure in each dog prior to bepridil infusion. A quadripolar electrode catheter (interelectrode distance 10 mm) was inserted via the right external jugular vein and positioned with the proximal electrode pair in the high right atrium to allow atrial pacing while the distal pair recorded the atrial electrogram. A bipolar catheter was inserted vic the left internal carotid artery and advanced into the root of the aorta until optimum His-bundle recordings were obtained. The heart was exposed through a right thoracotomy in the fifth intercostal space. A bipolar plaque electrode was sutured to the mid-right atrium approximately $1.5 \mathrm{~cm}$ f the sinoatrial (SA) node toward the right atrial appendage. Another bipolar plaque electrode was sutured to the right ventricle near its junction with the right atrium, thus allowing the delivery of a second pacing stimulus $\left(S_{2}\right)$ to either the atrium or the ventricle during atrial pacing via the tranvenous atrial electrode. Plaque electrodes were used to eliminate artifactual differences in the measured clectrophysiologic parameters that might result from slight changes in the position of the transvenous electrode. Determinations of sinoatrial conduction time (SACT) and corrected sinus node recovery time (CSNRT) were made during pacing via the proximal pair of electrodes of the transvenous right atrial electrode. The atrial electrogram, ECG, and His-bundle electrogram were continuously displayed using a Tektronix oscilloscope while intermittent recordings of these paraneters along with blood pressure were made at designated intervals using a Gould ES-1000 recorder with filter settings of $40-300 \mathrm{~Hz}$ (Fig 1). Measurements of the various inter:als were made from these recordings. High right atrial pacing
Fig 1. Example of the recordings from which measurements wore made. Each tracing is labeled at the left margin. The second tracing is a His-bundle (His)tracing and the atrial-His (AH) and His-Ventricular (HV) intervals are demonstrated. Abbreviations: Atrial, atrial electrogram; BP, blood pressisure; Stimulus, recording of pucing stimuli.

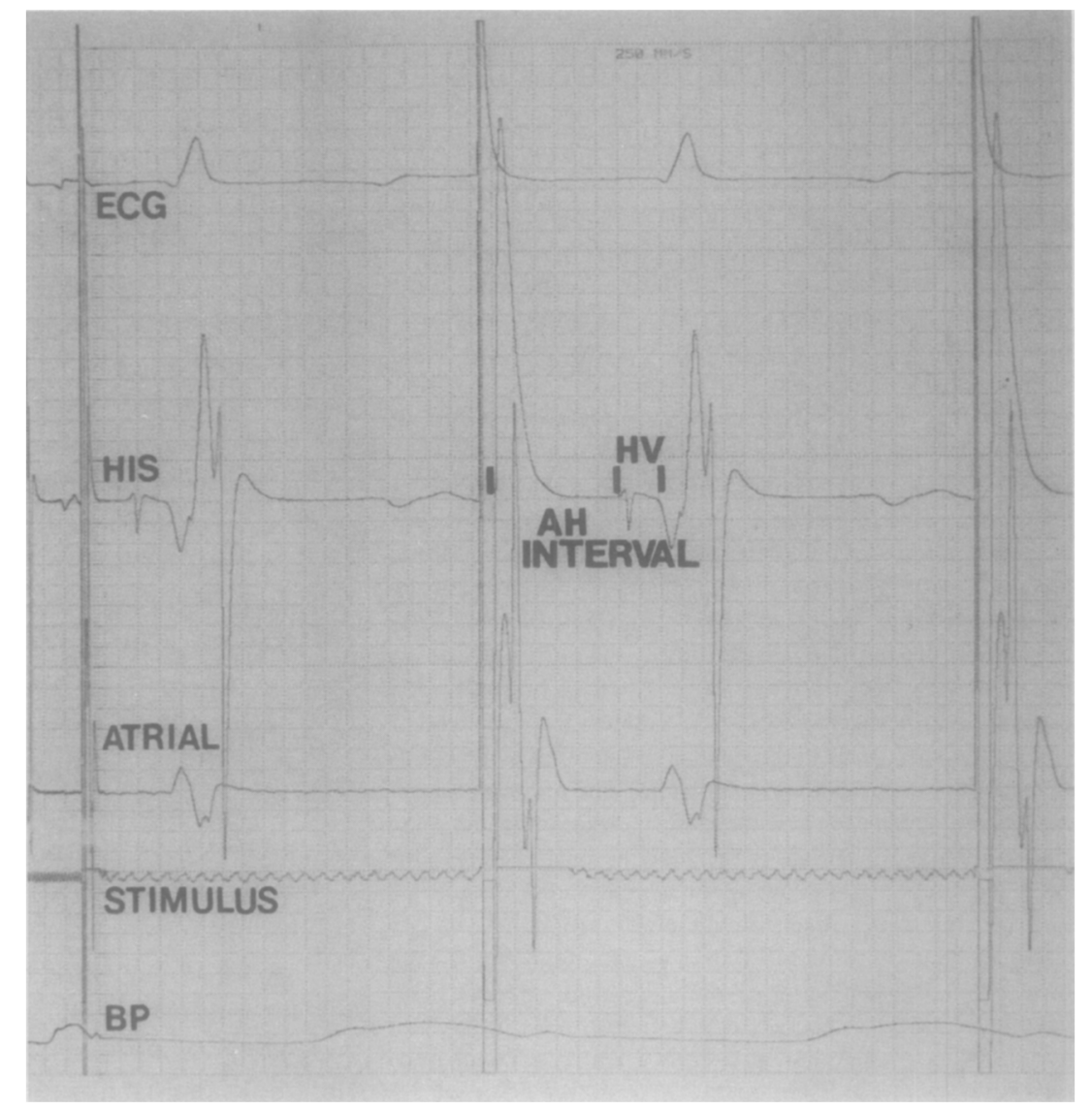


and the delivery of atrial and ventricular $S_{2}$ stimuli were achieved using a Grass S88 stimulator with the current measured and maintained at three times threshold, as determined at the beginning of each measurement. Esophageal temperature was measured and maintained at 36 to $38^{\circ} \mathrm{C}$ using a Yellow Springs Model 73A temperature controller. Arterial blood gases, serum potassium, sodium, calcium, and $\mathrm{pH}$ were measured periodically and maintained within the physiologic range.

After completion of the surgical preparation, baseline measurements of the following parameters were recorded: Sinus heart rate, SACT and CSNRT, atrial-His (AH) and His-ventricular (HV) intervals at pacing rates of 150,180 , and 200 beats/min (bpm), Wenckebach periodicity, and atrial and ventricular effective refractory periods at atrial pacing rates of $120 \mathrm{bpm}$. Sinoatrial conduction time was measured as described by Narula et al. ${ }^{16}$ High right atrial pacing was performed at $5 \%$ to $10 \%$ above the sinus heart rate for eight to ten paced beats and then halted. Sinoatrial conduction time was $50 \%$ of the difference obtained when the prepacing P-P interval was subtracted from the interval between the last paced atrial beat and the first sinus escape beat on the atrial electrogram. Corrected sinus node recovery time was determined by pacing with the high right atrial electrode for 30 seconds at heart rates of 150,180 , and 200 bpm with a one-minute rest period before each pacing interval. The first escape beat after the cessation of pacing determined the sinus node recovery time, which was defined as the interval from the last paced atrial depolarization to the first sinus escape beat measured on the atrial electrogram. The corrected sinus node recovery time was taken as the sinus node recovery time interval minus the immediate prepacing P-P interval at each pacing rate $(150,180,200 \mathrm{bpm})$. The highest of these values was recorded as the CSNRT. The AH bundle interval and the $\mathrm{HV}$ interval were determined at paper speeds of $250 \mathrm{~mm} / \mathrm{s}$ at the rates noted. Wenckebach periodicity was obtained by increasing the atrial pacing rate from slightly greater than spontaneous heart rate by 15 to 20 bpm after even ten paced beats until Wenckebach periodicity was observed and recorded.

Atrial and ventricular effective refractory periods were determined by pacing with the high right atrial electrode at a rate of $120 \mathrm{bpm}$ and inserting an extra atrial or ventricular stimulus of three times diastolic threshold via the plaque electrodes. These extra stimuli were introduced into atrial or ventricular diastole with increasing prematurity in 10-ms increments each eight to ten atrially paced beats until the atrium or ventricle was refractory. The longest atrially paced $P-S_{2}$ or $V-S_{2}$ intervals without atrial or ventricular capture and the shortest $P-S_{2}$ or V-S intervals with atrial or ventricular capture were recorded, and the refractory periods taken as the mean of these two values. The above measurements obtained in each anesthetized dog prior to the administration of bepridil served as the baseline measurements for each individual dog. Following the completion of these baseline measurements, bepridil, dissolved in $40 \mathrm{~mL}$ of $5 \%$ ethanol, was administered IV over 40 minutes using a Sage Model 350 infusion pump. Although faster infusion rates have been used by others, ${ }^{17}$ it was found to be difficult to maintain acceptable blood pressures when these faster infusion rates were used. Groups $1,3,5$, and 7 received 2.5 $\mathrm{mg} / \mathrm{kg}$, while groups $2,4,6$, and 8 received $5.0 \mathrm{mg} / \mathrm{kg}$ of bepridil. Four additional animals anesthetized with enflurane, halothane, isoflurane, and chloralose, respectively, were given $40 \mathrm{~mL}$ of $5 \%$ ethanol alone. The electrophysiologic measurements noted above were then repeated at $5,15,30$, 45 , and 60 minutes following the conclusion of the bepridil infusion.

Heparinized $5 \mathrm{~mL}$ arterial blood samples were obtained at the times noted above and stored in ice until the conclusion of the experiment. Following each experiment the plasma was separated from each sample using a Backman J6B refrigerated centrifuge. The frozen samples were shipped to the Department of Drug Metabolism of McNeil Pharmaceutical Company, Spring House, PA, where bepridil levels were determincd by high-performance liquid chromatography (HPLC) assay. ${ }^{18}$

The effects of bepridil were examined in the presence of the four anesthetics using paired Student $t$ tests with the Bonferroni correction. Differences among anesthetics were analyzed using profile analysis and analysis of variance with Scheffe corrections for multiple comparisons. When group variances were unequal, the nonparametric Kruskal-Wallis and median tests were performed. ${ }^{19}$

\section{RESULTS}

In animals anesthetized with enflurane, heart rate decreased from a baseline rate of $100 \pm 8 \mathrm{bpm}$ to $82 \pm 6 \mathrm{bpm}$ at the five-minute observation following $2.5 \mathrm{mg} / \mathrm{kg}$ of bepridil. Heart rate was less than $87 \mathrm{bpm}$ during the remainder of the observation period in these animals. In animals anesthetized with halothane, heart rate decreased from a baseline value of $108 \pm 10 \mathrm{bpm}$ to a rate of $88 \pm 8 \mathrm{bpm}$ at the five-minute measurement following $2.5 \mathrm{mg} / \mathrm{kg}$ of bepridil. Heart rate continued to be depressed at rates less than $93 \mathrm{bpm}$ throughout the observation period. In animals anesthetized with isoflurane, heart rate decreased from a baseline value of $103 \pm 3 \mathrm{bpm}$ to a rate of $95 \pm 5 \mathrm{bpm}$ at the five-minute measurement following $2.5 \mathrm{mg} / \mathrm{kg}$ of bepridil. Heart rate returned to levels measured prior to bepridil administration at the 15-minute measurement and remained at this rate during the remainder of the observation period. All values stated are significant decreases $(P<.05)$. In animals anesthetized with chloralose, the decrease in heart rate reached significance only at the five-minute measurement. Heart rate was decreased in all groups of animals throughout the observation periods following 5 $\mathrm{mg} / \mathrm{kg}$ of bepridil. There were no differences in the magnitude of change in heart rate among groups of animals anesthetized with enflurane, halothane, isoflurane, or chloralose (Fig 2). 


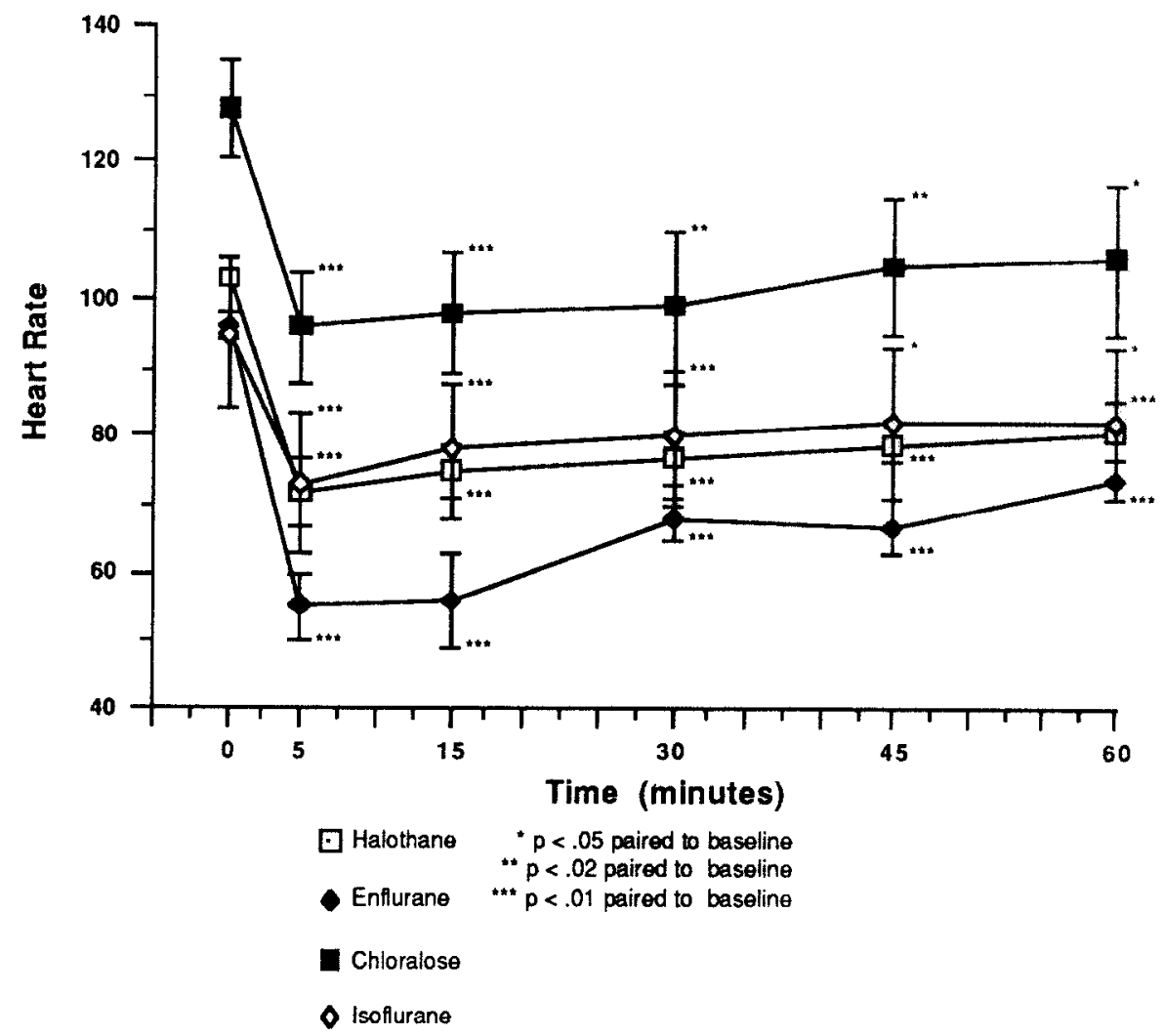

Fig 2. Serial changes in mean values \pm SD of heart rate $(\mathrm{bpm})$ show effect of bepridil $(5 \mathrm{mg} / \mathrm{kg})$. Time 0 represents control values after induction. Times $5,15,30,45$, and 60 represent time periods following bepridil administration.

Sinoatrial conduction time was unchanged during the observation period in all groups following administration of either the 2.5- or $5-\mathrm{mg} / \mathrm{kg}$ dose of bepridil. There was, however, wide variability in the SACT following the administration of $5 \mathrm{mg} / \mathrm{kg}$ of bepridil in the group of animals anesthetized with enflurane (Table 1). Animals anesthetized with chloralose, halothane, or isoflurane demonstrated no prolongation of CSNRT at either the $2.5-\mathrm{mg} / \mathrm{kg}$ or the $5-\mathrm{mg} / \mathrm{kg}$ dose of bepridil. Mean values of CSNRT exceeded one second at all observation times in animals anesthetized with enflurane receiving $5 \mathrm{mg} / \mathrm{kg}$ of bepridil. These values were increased in the group anesthetized with enflu- rane $(4,640$ to $2,460 \mathrm{~ms} \pm \mathrm{SD})$ compared to the group anesthetized with chloralose (160 to 90 $\mathrm{ms} \pm \mathrm{SD})(P<.01)$, while values for the halothane and isoflurane groups were not increased (Table 2).

Atrial-His intervals were unchanged following the administration of bepridil, $2.5 \mathrm{mg} / \mathrm{kg}$, during any of the anesthetics evaluated. This interval was prolonged following bepridil, $5 \mathrm{mg} /$ $\mathrm{kg}$, in animals receiving all anesthetics (Fig 3). Baseline AH intervals were not different when anesthetic groups were compared. Animals anesthetized with enflurane and receiving $5 \mathrm{mg} / \mathrm{kg}$ of bepridil demonstrated prolongation of the $\mathrm{AH}$ interval throughout the 60 -minute observation

Table 1. Bepridil (5 $\mathrm{mg} / \mathrm{kg}$ ) Effect on SACT

\begin{tabular}{lcccccc}
\hline Anesthetic & Baseline & $5 \mathrm{~min}$ & $15 \mathrm{~min}$ & $\mathbf{3 0 \operatorname { m i n }}$ & $\mathbf{4 5} \min$ \\
\hline Chloralose & $50 \pm 24$ & $56 \pm 26$ & $40 \pm 8$ & $46 \pm 13$ & $38 \pm 23$ \\
Halothane & $38 \pm 10$ & $10 \pm 11$ & $35 \pm 9$ & $26 \pm 7$ & $43 \pm 15$ \\
Enflurane & $7 \pm 15$ & $50 \pm 59$ & $440 \pm 505$ & $362 \pm 318$ & $5 \pm 22$ & 14 \\
Isoflurane & $20 \pm 36$ & $24 \pm 30$ & $22 \pm 33$ & $7 \pm 32$ & $10 \pm 34$ & 17 \\
\hline
\end{tabular}

NOTE. All values are in $\mathrm{ms} \pm \mathrm{SD}$. 
Table 2. Bepridil (5 mg/kg) Effects on CSNRT

\begin{tabular}{lcccccc}
\hline Anesthetic & Baseline & 5 min & 15 min & 30 min & 45 min & 60 min \\
\hline Chloralose & $90 \pm 20$ & $160 \pm 40$ & $110 \pm 30$ & $90 \pm 20$ & $90 \pm 20$ & $90 \pm 30$ \\
Halothane & $70 \pm 10$ & $130 \pm 20$ & $200 \pm 100$ & $100 \pm 20$ & $100 \pm 10$ & $90 \pm 10$ \\
Enflurane & $10 \pm 60$ & $* 4,640 \pm 2,210$ & $* 4,600 \pm 1,950$ & $* 3,320 \pm 1,760$ & $* 3,440 \pm 1,760$ & $* 2,460 \pm 1,940$ \\
Isoflurane & $130 \pm 40$ & $180 \pm 30$ & $140 \pm 30$ & $160 \pm 40$ & $130 \pm 35$ & $150 \pm 20$ \\
\hline
\end{tabular}

NOTE. All values are $\mathrm{ms} \pm \mathrm{SD}$.

$* P<.01$ compared to chloralose (Kruskal-Wallis median).

period. Animals receiving halothane and isoflurane demonstrated moderate increases in this measurement, which maintained significance through the 45-minute measurement with halothane and through the 15-minute measurement with isoflurane. Animals receiving chloralose demonstrated an increase in the $\mathrm{AH}$ interval at the five-minute measurement only. Comparison of the four groups demonstrated that the $\mathrm{AH}$ interval was prolonged in animals anesthetized with enflurane following administration of 5 $\mathrm{mg} / \mathrm{kg}$ of bepridil when compared to animals anesthetized with the other anesthetics $(P<.05)$.

Animals anesthetized with enflurane and receiving $2.5 \mathrm{mg} / \mathrm{kg}$ of bepridil demonstrated an increase in the Wenckebach $R-R$ interval through 45 minutes of observation when compared to baseline measurements. This parameter also increased in animals anesthetized with halothane, isoflurane, and chloralose. Animals anesthetized with enflurane and receiving $5 \mathrm{mg} / \mathrm{kg}$ of bepridil had prolongation of the Wenckebach R-R interval throughout the 60 -minute observation period $(P<.01)$. Animals anesthetized with chloralose, halothane, and isoflurane while receiving $5 \mathrm{mg} / \mathrm{kg}$ of bepridil demonstrated increases in the Wenckebach R-R interval for 45 minutes following bepridil administration. Group comparisons revealed that the prolongation of the Wenckebach R-R interval in animals anesthetized with enflurane was greater than

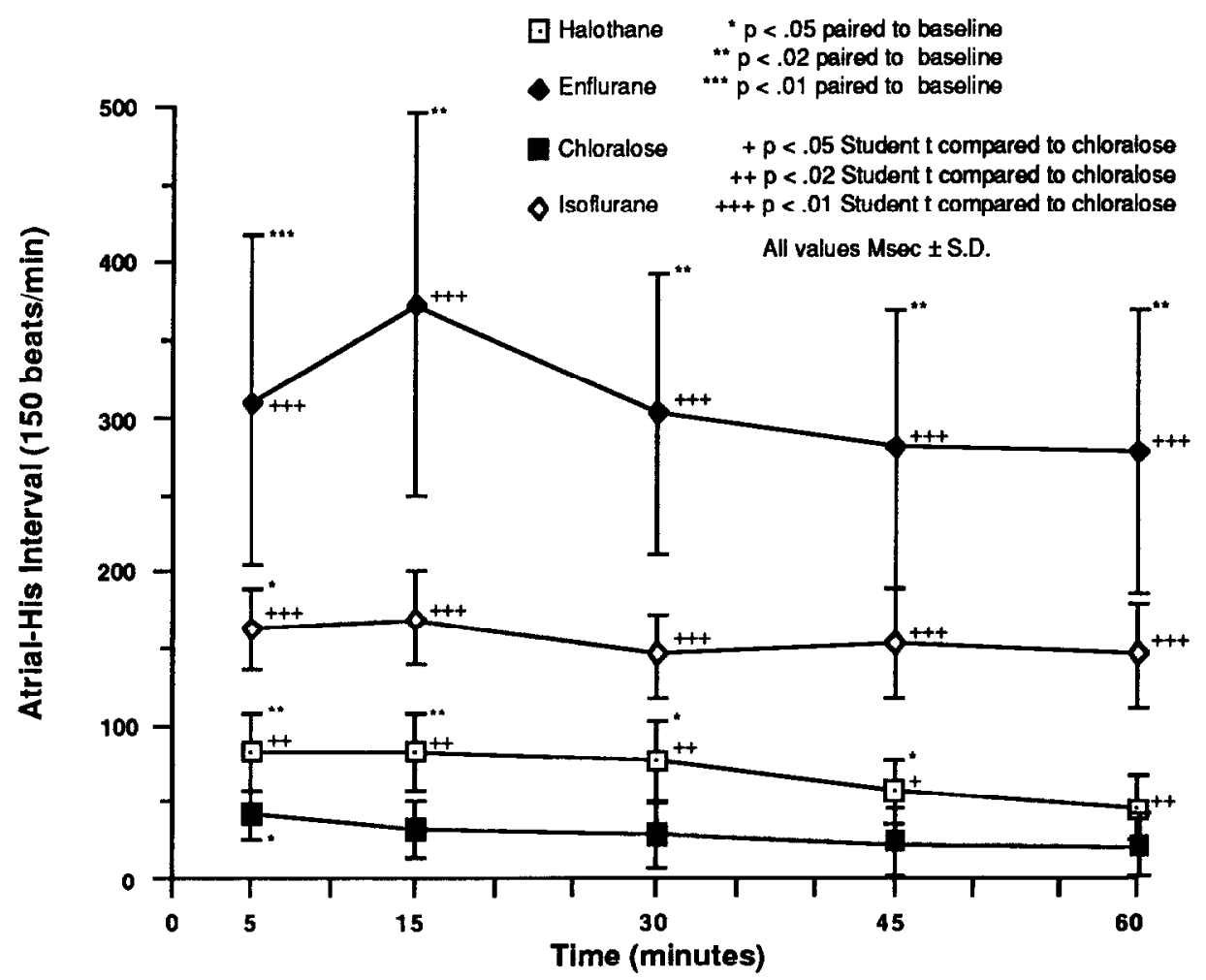

Fig 3. Serial changes in atrial-His intervals $(160 \mathrm{beats} / \mathrm{min})(\mathrm{mean}$ values $\pm \mathrm{SD}$ ) show effect of bepridi $(5 \mathrm{mg} / \mathrm{kg})$. Values represent changes from control values at $5,15,30,45$, and 60 minutes following bepridil administration. 


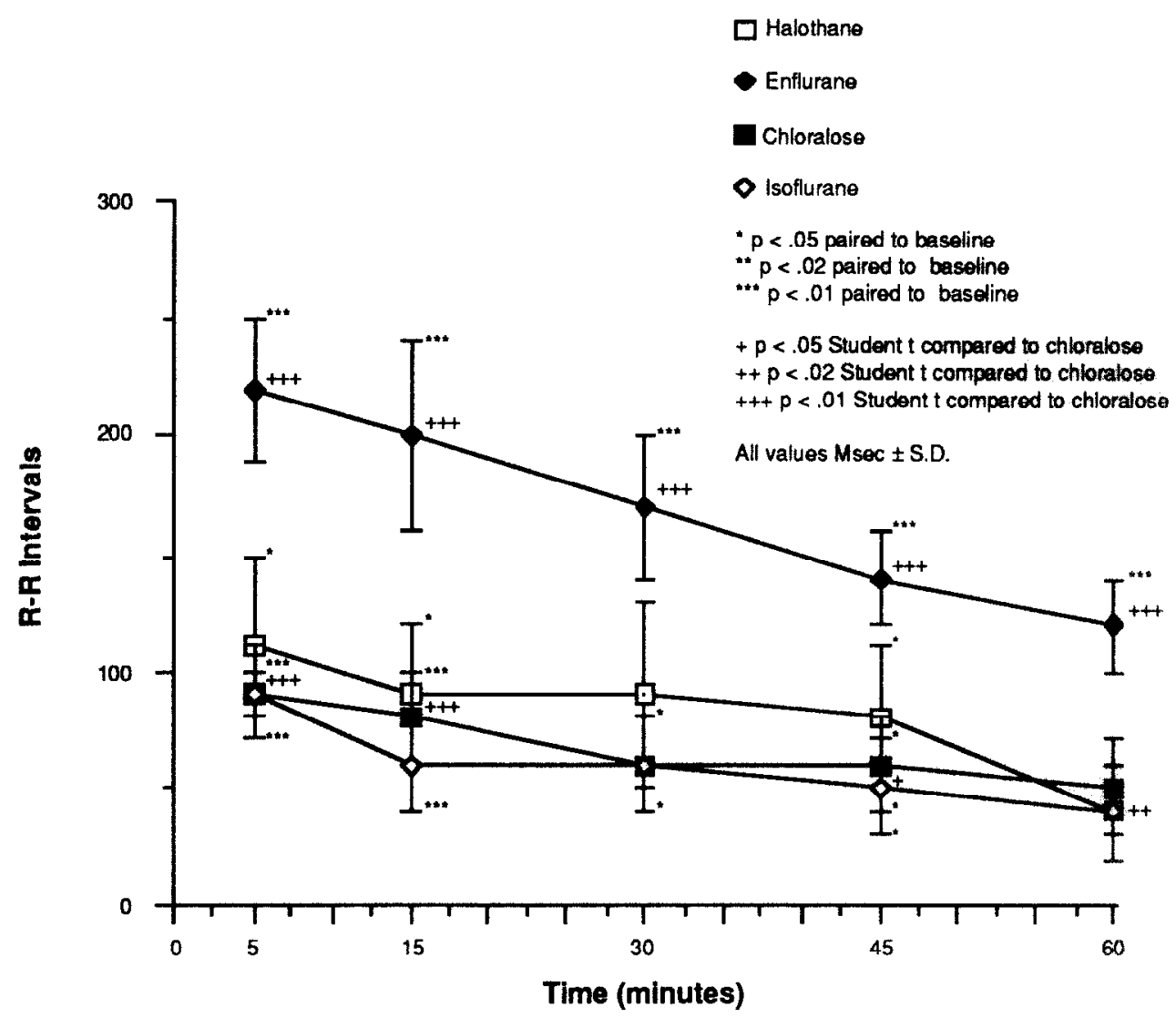

Fig 4. Serial changes in Wenckebach R-R intervals (mean values \pm SD) show effect of bepridil $(5 \mathrm{mg} / \mathrm{kg}$ ). Vaives represent changes from control values $5,15,30,45$, and 60 minutes following bepridil administration.

that observed in animals anesthetized with chloralose, halothane, or isoflurane following administration of bepridil, $5 \mathrm{mg} / \mathrm{kg},(P<.01)$ (Fig 4$)$. Values obtained prior to bepridil administration were not different when anesthetic groups were cormpared (chloralose $250 \pm 30 \mathrm{~ms}$, halothane $290 \pm 40 \mathrm{~ms}$, isoflurane $260 \pm 30 \mathrm{~ms}$, enflurane $280 \pm 40 \mathrm{~ms}$ ).

Atrial effective refractory period was increased in all animals following administration of $5 \mathrm{mg} / \mathrm{kg}$ of bepridil (Table 3 ). The increase observed in the group of animals anesthetized with enflurane was greater than those observed in the groups of animals anesthetized with chloralose, halothane, or isoflurane.

Ventricular effective refractory period was unchanged in all groups following $2.5 \mathrm{mg} / \mathrm{kg}$ of bepridil, while this measurement was prolonged in all groups following $5 \mathrm{mg} / \mathrm{kg}$ of bepridil. There were no group differences in bepridil's

Table 3. Bepridil (5 mg/ kg) Effects on Atrial Effective Refractory Periods Reported as Increase From Baseline Values

\begin{tabular}{|c|c|c|c|c|c|}
\hline Anesthetic & $5 \mathrm{~min}$ & $15 \mathrm{~min}$ & $30 \mathrm{~min}$ & $45 \mathrm{~min}$ & $60 \mathrm{mins}$ \\
\hline Halothane & $37 \pm 14^{*}$ & $33 \pm 19$ & $34 \pm 12^{*}$ & $40 \pm 18$ & $27 \pm 9$ \\
\hline Isoflurane & $27 \pm 19^{*}$ & $22 \pm 16$ & $26 \pm 22^{*}$ & $13 \pm 22$ & $22+13$ \\
\hline
\end{tabular}

NOTE. All values are in $\mathrm{ms} \pm \mathrm{SD}$.

$* P<.05$ paired to baseline.

$\dagger P<.01$ paired to baseline.

$t^{P}<.02$ Student's $t$ compared to chloralose.

$\S P<.01$ Student's $t$ compared to chloralose.

$\| P<.05$ Student's $t$ compared to chloralose. 
Table 4. Bepridil (5 mg/kg) Effects on Ventricular Effective Refractory Periods Reported as Increase From Baseline Values

\begin{tabular}{llllll}
\hline Anesthetic & 5 min & $15 \min$ & $30 \min$ & 45 min & 60 min \\
\hline Chloralose & $40 \pm 8$ & $37 \pm 8$ & $36 \pm 6$ & $34 \pm 8$ & $24 \pm 10$ \\
Halothane & $33 \pm 16$ & $30 \pm 20$ & $16 \pm 13$ & $20 \pm 10$ & $20 \pm 9$ \\
Enflurane & $38 \pm 26$ & $40 \pm 25$ & $18 \pm 17$ & $49 \pm 13$ & $40 \pm 6$ \\
Isoflurane & $35 \pm 11$ & $32 \pm 13$ & $24 \pm 9$ & $21 \pm 10$ & $20 \pm 8$ \\
\hline
\end{tabular}

NOTE. All values are in $\mathrm{ms} \pm \mathrm{SD}$.

effects on ventricular effective refractory period (Table 4).

Plasma concentrations of bepridil in the groups were not different following either dose during anesthesia with any of the anesthetics tested (Tables 5 and 6). Bepridil concentrations fell rapidly immediately after infusion of both doses of bepridil. The decline in plasma concentrations became slower thereafter. This drop in plasma bepridil levels is not inconsistent with the drug's long half-life, for it is unlikely that the linear portion of the elimination curve was reached during the course of the experiment.

Intravenous administration of $40 \mathrm{~mL}$ of $5 \%$ ethanol, the solvent in which bepridil is dissolved, had no effect on any measurement at any time during the 60 -minute observation period.

\section{DISCUSSION}

The cardiac electrophysiologic interactions between the volatile anesthetics and various calcium antagonists have been previously investigated. Significant abnormalities in both SA and AV nodal functions have been reported in dogs anesthetized with the volatile anesthetics and given verapamil. ${ }^{20,21}$ During isoflurane anesthesia, dogs receiving diltiazem have demonstrated sinus node arrest with junctional escape rhythms, ${ }^{22,23}$ while in one series second-degree heart block was also demonstrated.

Bepridil is a unique addition to the group of calcium antagonists. Its long half-life, as well as its fast sodium channel blocking and antidysrhythmic properties, may expand the indications for this class of drugs. ${ }^{7,8}$ Its apparent ability to prevent reperfusion tachydysrhythmias and ventricular fibrillation' make it an even more attractive drug to the research scientist and perhaps ultimately to the practicing physician. Importantly, bepridil serum levels persist in patients for increased periods following its discontinuance because of its prolonged half-life. Therefore, the potential for interactions with volatile anesthetic agents also persists despite discontinuance of the drug.

Sassine et al, ${ }^{17}$ investigating the cardiac electrophysiologic effects of IV-administered bepridil in dogs anesthetized with pentobarbital, reported a decrease in sinus heart rate, a prolongation of sinoatrial node recovery time, an increase in atrial refractory period, a slowing of $\mathrm{AV}$ nodal conduction and an increase in AV nodal refractoriness, and a lengthening of Wenckebach periodicity. Singh et $\mathrm{al},{ }^{4}$ studying the cardiac electrophysiologic effects of IVadministered bepridil in unanesthetized humans, reported a decrease in sinus heart rate, an increase in the $\mathrm{AH}$ bundle interval, and an increase in the refractory period of the atrialventricular node with a lengthening of the Wenckebach periodicity. These studies have demonstrated the electrophysiologic effects of bepridil alone and in combination with barbiturates. Interactions of bepridil with volatile anesthetics have not been addressed., ${ }^{4,17}$

In this study, sinus node function was assessed by three measurements: spontaneous heart rate, CSNRT, and SACT. Changes in spontaneous heart rate reflect a combination of

Table 5. Serum Concentrations in $\mathbf{n g} / \mathbf{m L}$ Following Bepridil, $2.5 \mathrm{mg} / \mathbf{k g}$

\begin{tabular}{|c|c|c|c|c|c|}
\hline Anesthetic & $5 \mathrm{~min}$ & $15 \mathrm{~min}$ & $30 \mathrm{~min}$ & $45 \mathrm{~min}$ & $60 \mathrm{~min}$ \\
\hline Halothane & $800 \pm 190$ & $470 \pm 140$ & $370 \pm 100$ & $310 \pm 110$ & $260 \pm 90$ \\
\hline Isoflurane & $670 \pm 310$ & $440 \pm 250$ & $340 \pm 210$ & $240 \pm 160$ & $270 \pm 220$ \\
\hline
\end{tabular}

NOTE. Values are means \pm SD. 
Table 6. Serum Concentrations in $\mathrm{ng} / \mathrm{mL}$ Following Bepridil, $5.0 \mathrm{mg} / \mathbf{k g}$

\begin{tabular}{lcrrrr}
\hline Anesthetic & $5 \mathrm{~min}$ & $\mathbf{1 5} \mathrm{min}$ & $\mathbf{3 0} \mathrm{min}$ & $\mathbf{4 5} \mathrm{min}$ \\
\hline Chloralose & $1,370 \pm 660$ & $1,060 \pm 560$ & $\mathbf{8 4 0 \pm 5 6 0}$ & $680 \pm \mathbf{4 1 0}$ & $560 \pm 330$ \\
Halothane & $1,770 \pm 580$ & $1,310 \pm 390$ & $1,120 \pm 420$ & $940 \pm 350$ & $870 \pm 390$ \\
Enflurane & $2,040 \pm 770$ & $1,190 \pm 500$ & $850 \pm 370$ & $690 \pm 320$ & $580 \pm 240$ \\
Isoflurane & $2,050 \pm 730$ & $1,400 \pm \mathbf{4 1 0}$ & $1,040 \pm 290$ & $880 \pm 320$ & $730 \pm 200$ \\
\hline
\end{tabular}

the direct and indirect autonomic effects of bepridil. Bepridil decreased heart rate in all groups during the observation period. These results are consistent with those obtained in animals anesthetized with pentobarbital and with data obtained in clinical trials. ${ }^{4,19}$

Corrected sinus node recovery time, once thought to be strictly a reflection of sinus node automaticity, is now the most widely used measurement of sinus node function. ${ }^{24}$ The mechanism of prolongation of the CSNRT is of uncertain etiology, although an abnormally prolonged CSNRT does occur secondary to sinoatrial exit block. ${ }^{25}$ SACT was measured to elucidate the mechanism for the prolongation of CSNRT. All animals had CSNRT of less than $500 \mathrm{~ms}$ at the control measurement. Sinoatrial conduction time did not increase following either 2.5 or $5 \mathrm{mg} / \mathrm{kg}$ of bepridil in animals anesthetized with chloralose, halothane, or isoflurane. In contrast, markedly prolonged CSNRT of greater than three seconds occurred in four of seven animals receiving $5 \mathrm{mg} / \mathrm{kg}$ of bepridil during enflurane anesthesia. Two of the four animals in the enflurane group had prolonged SACT following the administration of $5.0 \mathrm{mg} / \mathrm{kg}$ of bepridil, while the other two animals did not. This suggests that sinoatrial conduction is important in explaining some, but not all, of the long sinus pauses following rapid atrial pacing. It is likely that the delay in CSNRT in the two animals with abnormal SACT was due to delay in the conduction of impulses out of the sinus node, ie, sinoatrial exit block. The other two animals in the enflurane and $5.0 \mathrm{mg} / \mathrm{kg}$ of bepridil group had prolonged CSNRT while demonstrating no abnormality in sinoatrial conduction, suggesting that depression of sinus node automaticity was the probable cause of prolongation of CSNRT in these two animals.

The effect of bepridil on atrioventricular nodal function was determined by assessment of the $\mathrm{AH}$ interval (at $150 \mathrm{bpm}$ ) and the Wencke- bach $\mathrm{R}-\mathrm{R}$ interval. The atrial His-bundle in erval at $150 \mathrm{bpm}$ is a measure of the conduction time through the AV node at this rate. The Wenckebach R-R interval correlates with the atrioventricular node effective refractory period. ${ }^{26}$ At the $2.5 \mathrm{mg} / \mathrm{kg}$ dose, the depressant effects of bepridil on A-V nodal function were similar in all anesthetized animals. Druginduced increases in refractoriness were videnced by the occurrence of Wenckebach phenomenon at slower heart rates. Atrial-His intervals at a rate of $150 \mathrm{bpm}$ were largely unaffected in any anesthetic group at this dose of bepridil. When bepridil, $5 \mathrm{mg} / \mathrm{kg}$, was administered, there were significant increases in conduction times and refractoriness of the A-V node in all anesthetic groups. The bepridil-induced increases were larger, however, in the animals anesthetized with enflurane. Although the A-V nodal depressant effects of bepridil were grester during enflurane anesthesia than during chloralose, halothane, or isoflurane anesthesia, these effects were more uniform than the depressant effects on the parameters of S-A node function. The potentially catastrophic depression of the S-A node was not noted in the depressant effects on the A-V node. No animal evidenced spontaneous second- or third-degree heart block.

The atrial effective refractory period was increased in animals receiving $5 \mathrm{mg} / \mathrm{kg}$ of bepridil and anesthetized with enflurane when compared to animals anesthetized with chloralose, halothane, or isoflurane. Bepridil, $5 \mathrm{mg} / \mathrm{kg}$, produced prolongation of the ventricular affective refractory period for 45 minutes of the observation period in animals anesthetized with chloralose and halothane, and for 60 minute: in animals anesthetized with enflurane and isolurane. These results are consistent with those of Sassine et al, who demonstrated a greater prolongation of the atrial effective refractory period than of the ventricular effective refractory period in animals anesthetized with pentobarbital and 
receiving $5 \mathrm{mg} / \mathrm{kg}$ of bepridil. ${ }^{17}$ In that study, bepridil prolonged atrial refractory period with a minimal effect on the duration of the atrial monophasic action potential. ${ }^{17}$

Serum bepridil levels at all measurement time periods and both dosages were comparable to those reported in both human volunteers and in patients treated with bepridil for angina in doses ranging from $200 \mathrm{mg}$ to $600 \mathrm{mg}$ orally (PO), daily. ${ }^{5}$ Although Sassine et $\mathrm{al}^{17}$ did not report serum levels in their canine study, the IV bepridil doses used in this study are comparable to those used in their study. Their results in pentobarbital-anesthetized dogs are comparable to the present chloralose-anesthetized animals. ${ }^{17}$

At the $5-\mathrm{mg} / \mathrm{kg}$ dose of bepridil, depression of sinus and atrioventricular nodal conduction and of atrial refractoriness were of greater magnitude and duration in animals anesthetized with enflurane than in animals anesthetized with chloralose, halothane, or isoflurane. This suggests that in the presence of enflurane bepridil inhibits slow calcium fluxes to a greater extent than in animals anesthetized with chloralose, halothane, or isoflurane. Consistent with this observation is the finding that the atrial effective refractory period is increased in animals receiving enflurane, suggesting that the inhibition of the calcium fluxes could be secondary to a delayed reactivation of the calcium channel. ${ }^{17}$

The combination of bepridil, $5.0 \mathrm{mg} / \mathrm{kg}$, and enflurane, $3.3 \%$ ( $\mathrm{MAC}=2.2 \%)$, caused severe sinus node dysfunction as measured by CSNRT. Since one of the potential clinical uses of bepridil is the treatment of supraventricular tachycardia, patients with a history of paroxysmal supraventricular tachycardia may be scheduled for surgery while receiving bepridil. The combination of enflurane and an episode of supraventricular tachycardia in these patients could result in conditions analogous to those present in this experiment following rapid atrial pacing. In addition, one enflurane-anesthetized animal demonstrated a SACT greater than 3.5 seconds (ie, a pause following pacing at a rate just greater than spontaneous heart rate), suggesting the existence of a potential for a severe bradyarrhythmia following the use of enflurane in patients taking bepridil in the absence of a history of supraventricular tachycardia. This suggests that caution should be used in the use of enflurane in patients receiving bepridil. Depressant effects on the atrioventricular node could not be demonstrated at the $2.5-\mathrm{mg} / \mathrm{kg}$ dose of bepridil (ie, no therapeutic effects were evident at this dose in dogs). A-V nodal depression was noted at the $5-\mathrm{mg} / \mathrm{kg}$ dose, which strongly suggests that this is an appropriate dose for study of this drug in dogs.

In summary, these data clearly demonstrate that the calcium-blocking actions of bepridil are more pronounced during enflurane anesthesia than during chloralose, halothane, or isoflurane anesthesia in dogs. Following the IV administration of $5 \mathrm{mg} / \mathrm{kg}$ of bepridil, severe sinus node dysfunction occurred in half of the animals anesthetized with enflurane. This was demonstrated both by prolonged CSNRT and by prolonged SACT. In at least two cases, the abnormal sinus node function was presumably due to sinoatrial node exit block. Atrioventricular nodal function is depressed more by bepridil in animals anesthetized with enflurane than in animals anesthetized with halothane, isoflurane, or chloralose. No spontaneous second- or thirddegree heart block was demonstrated, however, following either dose of bepridil with any of the anesthetic agents. In addition, if the pacing function of the sinus node is inhibited, other pacemakers in the atrioventricular junction cannot be relied upon to maintain heart rate since they are depressed by inhalational anesthetics. ${ }^{27}$

\section{REFERENCES}

1. Cohn JN: Symposium on bepridil: A new antianginal agent-Introduction. Am J Cardiol 55:1C-2C. 1985

2. Shapiro W, DiBianco R, Udho T, et al: Comparative efficacy of 200,300 , and $400 \mu \mathrm{g}$ of bepridil for chronic angina pectoris. Am J Cardiol 55:36C-42C, 1985

3. Narahara KA, Shapiro W, Woliky I, et al: Hemodynamic actions of bepridil during treatment of stable angina pectoris. Am J Cardiol 55:55C-58C, 1985

4. Singh BN, Koonlawec N, Feld G, et al: Comparative electrophysiologic profiles of calcium antagonists with particular reference to bepridil. Am J Cardiol 55:14C-19C, 1985

5. Benet L: Pharmacokinetics and metabolism of bepridil. Am J Cardiol 55:8C-13C, 1985

6. Tillament JP, Albengres E, Urien S, et al: Metabolisme et pharmacocinetique de bepridil chez l'homme. Rev Med 24:1265-1269, 1983

7. Schwartz A, Matlib M, Balweirczak J, Lathrop D: Pharmacology of calcium antagonists. Am J Cardiol 55:3C7C, 1985 
8. Brannan MD, Fortunato MA, Ash $\mathrm{C}$, et al: Bepridil (calcium blocker) increases ventricular fibrillation threshold in dog heart. Fed Proc 42:1345, 1983

9. Lynch J, Montgomery D, Ventura A, et al: Antiarrhythmic and electrophysiologic effects of bepridil in chronically infarcted conscious dogs. J Pharmacol Exp Ther $234: 72-80,1985$

10. Lynch C, Vogel S, Pratila MG, Sperelakis N: Enflurane depression of myocardial slow action potentials. J Phasmacol Exp Ther 222:405-409, 1982

11. Bosnjak ZJ, Kampine JP: Effects of halothane, enflurane, and isoflurane on the SA node. Anesthesiology 58:314-321, 1983

12. Blanck TJJ, Thompson M: Enflurane and isoflurans stimulate calcium transport by cardiac sarcoplasmic reticulum. Anesth Analg 81:142-145, 1982

13. Hantler CB, Felbeck PG, Kroll DA, et al: Effects of verapamil on sinus and AV nodal function in the presence of volatile anesthetics. Anesthesiology 59:A38, 1983

14. Kapur PA, Bloor BC, Flacke WE, et al: Comparison of cardiovascular responses to verapamil during enflurane isoflurane, or halothane anesthesia in the dog. Anesthesiology 61:156-160, 1984

15. Duchene-Marullaz P, Fabry-Delaigue R, Gueorguiey $G$, et al: Influence of chloralose and pentobarbitone sodium on atrioventricular conduction in dogs. Br J Pharmacol $77: 309-317,1982$

16. Narula OS, Shantha $N$, Vasquez M, et al: A new meinod for measurement of sinoatrial conduction time. Circulation 58:706-714, 1978

17. Sassine A, Masse C, Fajuri A, et al: Electrophysiologic effects of bepridil in the anesthetized dog studied by endocardial electrodes. Am J Cardiol 53:1707-1712, 1984
18. Hills JF, Ng KT: Liquid chromatographic determination of bepridil and its metabolites in plasma. Pharm Res (in press)

19. Morrison DF: Multivariate Statistical Methods. New York, McGraw-Hill, 1967, 186-197

20. Kapur PA, Bloor BC, Flack WE, et al: Comparison of cardiovascular responses to verapamil during enfurane, isoflurane, or halothane anesthesia in the dog. Anes hesiology 61: 156-160, 1984

21. Chelly JE, Rogers K, Hysing ES, et al: Cardiovascular effects of and interaction between calcium blocking drugs and anesthetics in chronically instrumented dog. I. Verapamil and halothane. Anesthesiology 64:560-567, 1986

22. Priebe HJ, Skaroan K: Cardiovascular and slectrophysiologic interactions between diltiazem and isofturane in the dog. Anesthesiology 66:114-121, 1987

23. Kapur PA, Campos JH, Tippit SE: Intuence of diltiazem on cardiovascular function and coronary hemodynamics during isoflurane anesthesia in the dog: Correlation with plasma diltiazem levels. Anesth Analg 65:81-87, 996

24. Josephson ME, Seides SF: Clinical Cardiac Electrophysiology. Philadelphia, Lea \& Febiger, 1979, p $64-68$

25. Gomes JAC, Hariman RI, Chowdry IA New application of direct sinus node recordings in man: Assessment of sinus node recovery time. Circulation $70: 663-1771$, 1984

26. Bisset JK, Kane JJ, de Soysan N, et al: Electrophysiological significance of rapid atrial pacing as a test of atrioventricular conduction. Cardio Kes 9:593-599, 1975

27. Hantler CB, Vandenbosch $M$, Landay $S$, er al: Ancsthetic cffects on $\mathrm{AV}$ node function in the presence and absence of thiopental. Anesthesiology 63:A80, 198 . 